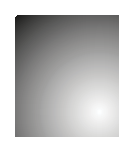

\title{
Conhecendo o Campo da Economia dos Custos de TrANSAÇÃO: UMA ANÁLISE EPISTEMOLÓGICA A PARTIR DOS trabalhos de Oliver Williamson
}

\author{
Understanding the Field of Transaction Cost Economics: an \\ epistemological analysis from Oliver Williamson's work
}

Cleunice Zanella

Doutoranda em Administracão pela Universidade Federal de Santa Catarina. Chapecó, SC, Brasil. E-mail: cleunice@unochapeco.edu.br

Daniel Gonçalves Lopes

Doutorando em Administração pela Escola de Administração de Empresas de São Paulo. Fundação Getúlio Vargas. São Paulo, SP, Brasil.E-mail: danielgoncalveslopes@gmail.com

André Luis da Silva Leite

Doutor em Engenharia de Produção e Professor do Departamento de Ciências da Administração da Universidade Federal de Santa Catarina (UFSC). Florianópolis, SC, Brasil.E-mail: andre.leite@live.com

Nei Antonio Nunes

Doutor em Sociologia Política Universidade Federal de Santa Catarina (UFSC). Professor do Programa de Pós-Graduação em Administração - UNISUL. Florianópolis, SC, Brasil.E-mail: neinunes@bol.com.br

\section{Resumo}

A Economia dos Custos de Transação (ECT) tem mostrado, nas últimas décadas, exercer forte influência em diversos campos do pensamento administrativo, por exemplo, estratégia. Este artigo tem como objetivo fazer uma análise epistemológica da ECT, com base nos trabalhos de Oliver Williamson, ganhador do Prêmio Nobel de Economia em 2009. Embora a ECT represente uma ruptura com o pensamento mainstream, ela também adota pressupostos otimizadores, o que significa forte influência do pensamento positivista sobre essa teoria. Ao final, são mostradas as principais correntes influenciadoras de Williamson e os principais pressupostos teóricos da ECT. Por fim, mostra-se que a ECT tem se revelado uma forte corrente teórica para explicar comportamento organizacional.

Palavras-chave: Economia dos Custos de Transação. Williamson. Organizações.

\section{Abstract}

The Transaction Costs Economics (TCE) has shown in recent decades exerting strong influence in many fields of thought, such as organization theory and strategy. This paper aims to make an epistemological analysis of the (TCE), on the basis of the work of Oliver Williamson, winner of the Nobel Prize in economics in 2009. Although TCE represents a break with the mainstream thinking, also adopts optimizers assumptions, which can be viwed as a strong influence of positivist thought on this theory. In the end, we show the influences on Williamson, as well as the main theoretical assumptions of TCE. Finally, it is shown that the TCE has been revealed as a strong current theory to explain organizational behavior.

Keywords: Transaction Costs Economics. Williamson. Organizations. 


\section{INTRODUÇÃO}

O desenvolvimento do conhecimento em ciências sociais tem sido, desde seus primórdios, fortemente marcado pelo paradigma positivista. Conforme Audet e Déry (1996), isso contribuiu sobremaneira para uma predominância do discurso cientificista nas pesquisas sociais desenvolvidas ao longo do século $\mathrm{XX}$. Nos estudos sobre a firma, as premissas e os critérios de validação positivistas fizeram com que a empresa persistisse como uma black box. Até a introdução do conceito de custos de transação não havia um argumento para a existência das firmas. A Economia dos Custos de Transação (ECT) surgiu como um esforço de desenvolvimento de uma Teoria da Firma e é um dos seguimentos da Nova Economia Institucional (NEI), cujas discussões partiram de Coase (1937) e ganharam fôlego com Williamson (1971, 1975, 1985, 1996).

Os trabalhos de Williamson aparecem em grande número nos últimos 30 anos em periódicos (FERNÁNDEZ; PESSALI, 2003). O seu arcabouço teórico tem como foco de análise o estudo sobre a formação das estruturas de governança (mercado, hierarquia $e$ forma híbrida), cujos pressupostos teóricos básicos são: a) os atributos de transação (frequência, incerteza e especificidade dos ativos); b) os pressupostos comportamentais (oportunismo e racionalidade limitada).

A partir do cenário apontado anteriormente e visando verificar os avanços na geração de conhecimento nas ciências sociais, torna-se necessário realizar análises epistemológicas interdisciplinares que visam estudar a produção do conhecimento científico tanto do ponto de vista lógico como linguístico, histórico, sociológico, ideológico e antropológico (SERVA, 2012). Nesse sentido, este artigo tem como objetivo apresentar uma reflexão epistemológica acerca da Economia dos Custos de Transação (ECT).

As seções seguintes apresentam uma síntese de algumas correntes epistemológicas relevantes ao debate sobre a Teoria da Firma e a análise dos pressupostos científicos da ECT. Para tanto, buscou-se contextualizar a "velha" e a "nova" economia institucional, os pressupostos teóricos da ECT e os fundamentos em que Williamson baseia a sua teoria.

\section{Trajetórias Epistemológicas: CONSTRUCTOS MODERNOS E CONTEMPORÂNEOS}

Este item apresenta uma breve contextualização de importantes matrizes epistemológicas, algumas delas emergentes na modernidade, mas com destacada presença e/ou influência no debate e na produção científicos em distintas áreas na contemporaneidade. Tal discussão visa, sobretudo, inventariar importantes paradigmas do conhecimento em ciências sociais que permita melhor situar os posicionamentos epistemológicos de Williamson e assim nuançar, nos demais pontos do artigo, suas posições teóricas e as implicações que delas decorrem.

De acordo com Japiassu (1991), por epistemologia pode-se entender o estudo metódico e reflexivo da ciência, seus fundamentos, procedimentos, organização, desenvolvimento, bem como o funcionamento de seus resultados intelectuais. Para o autor, os limites do domínio de investigação da epistemologia são muito flutuantes, dificultando sua conceituação bem como a delimitação precisa do seu espectro investigativo. Por seu caráter de disciplina interdisciplinar, permite estudar a produção de conhecimentos tanto do ponto de vista lógico quanto linguístico, sociológico, ideológico, etc., o que permite o confronto, mas também a interface, entre distintas concepções de conhecimento, de áreas do saber e de perspectivas metodológicas.

Há que considerar também que, em desacordo com determinadas correntes como a positivista, $e$ apesar da flexibilidade do campo epistemológico, os discursos e as práticas científicas acabam, de certo modo - como será verificado - por serem moldados pela visão epistemológica do epistemólogo/pesquisador. Sobre este ponto, cabe um alerta. O papel do epistemólogo, frente ao campo de estudo, não é o de constituir um sistema dogmático que ditaria autoritariamente o que deveria (ou não) ser o critério da verdade científica. Crê-se, pois, que essa inferência se aplica às investigações empíricas e também aquelas eminentemente teóricas, ou seja, tanto as pesquisas definidas como quantitativas quanto as qualitativas. A emergência dessa reflexão, contudo, é anterior à contemporaneidade. Isto é, o aparecimento da noção de "sujeito do conhecimento" e do debate sobre as diferenças e similitudes dos constructos epistemológicos 
emerge na tradição moderna com o confronto entre teses empiristas e racionalistas.

\subsection{Correntes Epistemológicas: divergências e similitudes}

Dentre os teóricos modernos com destacada participação no debate entre as abordagens racionalista e empirista, destacam-se nomes como Francis Bacon (1561-1626), René Descartes (1596-1650) e Immanuel Kant (1724-1804). O empirista Bacon (1979), por exemplo, considera que existem dois caminhos de geração e propagação de doutrinas do saber: a "Antecipação da Mente" (destinado ao cultivo das ciências) e "Interpretação da Natureza" (destinado à descoberta científica). Como filósofo e cientista, ele assume o segundo desafio. Para tanto, defende a utilização de um método para interpretação da natureza, em vez de apenas emitir opinióes prováveis e/ou metafísicas. A experiência, portanto, é a base para o conhecimento. Contudo, não há garantias que o experimento isolado (que pode até gerar a solução de um problema pontual), proporcione progresso substantivo na ciência. Para que isso ocorra, é necessário utilizar um método ordenado, visando identificar as causas, os axiomas etc. Assim, "[...], em qualquer espécie de experiência, deve-se primeiro descobrir as causas e os axiomas verdadeiros, buscando os axiomas lucíferos e não os axiomas frutíferos [...]" (BACON, 1979, p. 39). Com essa proposição, adverte que na ânsia de recolher os frutos gerados por seus experimentos, além da reputação, os homens, prematuramente, se voltam para a prática, interrompem a busca pelas causas e as questões axiomáticas. Com o intuito de superar as conclusões extraídas da doxa, como efeito de um empirismo ingênuo, acrescenta: "[...] quando a experiência proceder de acordo com leis seguras e de forma gradual e constante, poder-se-á esperar algo de melhor da ciência”. (BACON, 1979, p. 66). Para tanto, Bacon apresenta um método de interpretação baseado na indução. Nessa perspectiva, conclui com a seguinte advertência: "[...] não se deve inventar ou imaginar o que a natureza faz ou produz, mas descobri-lo". (BACON, 1979, p. 102)

Descartes (1979), considerado precursor do racionalismo moderno, não ignora a importância da empírica no conhecimento, mas salienta que os crivos da razão abstrata e do método dedutivo permitem evitar os equívocos gerados pelos sentidos humanos (que são enganosos e, por isso, podem iludir o sujeito que busca a verdade), como também propiciar um conhecimento mais rigoroso do mundo natural e humano. Sem abrir mão da matematização e do mecanicismo, indica os seguintes preceitos investigativos: 1) jamais escolher alguma coisa como verdadeira que não conhecesse como tal; 2) dividir cada uma das dificuldades que examinasse em tantas parcelas quantas possíveis e quantas necessárias fosse para melhor resolvê-las; 3) conduzir por ordem os pensamentos, começando pelos objetos mais simples e mais fáceis de conhecer; 4) fazer em toda parte enumerações tão completas e revisões tão gerais, que tivesse a certeza de nada omitir. Verifica-se, pois, que para Descartes o acesso à verdade (filosófica ou científica) pressupõe o uso de um método rigoroso que está ancorado primeiramente na razão.

Assim como Bacon, o teórico racionalista aposta na prática constante do método como caminho possível e seguro para gerar conhecimento. Mas, enquanto Bacon vê na observação por meio da empiria e da indução o acesso para desvendar os distintos fenômenos, Descarte opta pelo racionalismo como condição para chegar às substâncias constantes e verdadeiras.

O filósofo Immanuel Kant interessou-se desde cedo pelo estudo de temas oriundos de diferentes áreas do conhecimento, a saber, ciência, ética, política e estética. Mas quando analisa os limites e possibilidades do conhecimento, em sua Crítica da razão pura, chama a atenção para o saber que não se oferece de imediato a experiência sensível. Também não se trata, para ele, de fundar o conhecimento em essências metafísicas, pois ele se fundamenta, sobretudo, na razão que visa captar os fenômenos tal qual se apresentam ao sujeito. Assim, Pimenta explicando Kant assevera: “[...] se nós conhecemos algo das coisas, é porque é a nossa razão que institui as regras que possibilitam todo e qualquer conhecimento" (PIMENTA, 2008, p. 17). Diga-se a respeito, ao propor como base investigativa o "[...] tribunal da razão [...]", dirá Kant que todo conhecimento deriva da experiência e depende dela "[...] mas não dispensa o pressuposto do racionalismo: induções deixadas a si mesmas não dizem nada, todo sentido depende de uma instância separada da experiência e independente dela, a própria razão [...]" (PIMENTA, 2008, p. 17). Não cabe ao "[...] sujeito do conhecimen- 
to [...]" - termo cunhado na modernidade e central no criticismo kantiano - conhecer o noumenon (ou seja, a essência das coisas, as coisas em si mesmas), mas os "fenômenos" e, para tanto, seria fundamental não negligenciar, no processo investigativo, os âmbitos a priori (razão pura) e a experiência sensível. Contudo, é preciso salientar que ao deslocar, na pesquisa, o ato de conhecer do "objeto" para o "sujeito (do conhecimento)", Kant concebe a razão como a condição de possibilidade da experiência. Num esforço analítico, Braga e Braga (2014, p. 67) assim sintetizam as proposições kantianas:

a) O objeto do conhecimento é a realidade "para nós", distinta da realidade "em si mesma".

b) O objeto do conhecimento (realidade para nós) é construído pela atividade cognitiva do sujeito: atividade pela qual o sujeito impõe a tudo o que aparece (fenômenos) uma estrutura lógico-conceitual única e abrangente, própria da sua mente (do sujeito). [...]

c) O conhecimento científico é rigorosamente necessário. Mais precisamente: a estrutura formal, lógico-conceitual, é infalível, embora possamos eventualmente nos enganara em relação aos conteúdos que a preenchem.

Nos termos propostos por Minayo (2014), Kant induz a pensar que "[...] diante [do escrutínio do objeto], a abordagem quantitativa e qualitativa produzirá a unidade sintética do múltiplo e do uno". E acrescenta: "Ao se juntarem, as especificidades metodológicas não se dissolvem, continuam a existir no trato com questões que exigem uma ou outra abordagem como mostram a base filosófica de Kant [...]", entre outras. (MINAYO, 2014, p. 365) Todavia, vê-se que, a revelia do advento de importantes constructos em ciências sociais e humanas, matrizes teóricas dos séculos XIX e XX hierarquizaram metodologias e objetos de investigação, desqualificando, em tantos momentos, áreas de saber e campos investigativos.

De passagem, cabe indicar que para o positivismo oitocentista o conhecimento científico deveria se restringir ao escrutínio dos fenômenos observáveis, a saber, aos fatos extraídos da experiência. Em posição diametralmente oposta ao indicado anteriormente, depreende-se desta concepção de conhecimento a defesa da neutralidade científica do cientista-pesquisador, haja vista a convicção do positivismo de Auguste
Comte (1798-1857) no caráter integralmente objetivo da ciência. O pensador francês também sustenta que o progresso da ciência é um fato inexorável. (COMTE, 1978). De certo modo, no século XX o neopositivismo aprofunda as pretensões do autor, na medida em que, no afã de rejeitar os fundamentos metafísicos do conhecimento, almeja dar as bases para uma ciência unificada com método universal.

Os idealizadores do "positivismo lógico" - outra denominação atribuída a teoria proposta nos anos de 1930 pelos membros do "Círculo de Viena" sustentam que o conhecimento científico deve ser fundado nos fatos da observação (tese já defendida pelo positivismo clássico). Mas a novidade agora seria, sobretudo, o estabelecimento do crivo da estrutura lógica como condição de validação dos argumentos teóricos, que indicaria se estes seriam de fato científicos ou meramente especulativos. Para os neopositivistas, a experiência deveria ser traduzida por linguagem logicamente coerente, a saber, por proposições lógicas e mensuráveis. $\mathrm{O}$ "princípio de verificabilidade" pelo qual seria possível refutar as teorias (de bases metafísicas), que careceriam de significado científico, estaria ancorado na ideia de que a lógica, a matemática e o saber empírico formam, em conjunto, o substrato de um método universal, condição para a verdadeira ciência.

Como sintetizam Braga e Braga (2014), o empirismo lógico do século XX procura estabelecer "[...] uma justificação probabilística, usando um tipo de lógica indutiva" (BRAGA; BRAGA, 2014, p. 84). De certo modo, tanto o positivismo clássico quanto o neopositivismo sofreram duras críticas na contemporaneidade. O insucesso de erigir um método universal para distintas ciências, e certa sacralização da objetividade e da neutralidade científicas, idealizadas por positivistas e neopositivistas, foram postas em xeque, por exemplo, por epistemólogos como Karl Popper (1902-1994), Thomas Kuhn (1922-1996) e Paul Feyerabend (19241994). A propósito, o variegado campo de metodologias gerado nas ciências sociais e humanas, no século $\mathrm{XX}$ e neste limiar no novo milênio, vem propiciando a emergência de inauditas abordagens epistemológicas que questionam, em certa medida, os pilares das teorias positivista e neopositivista.

Apesar das diferenças expressivas entre suas concepções epistemológicas, os três teóricos citados 
operam um verdadeiro deslocamento no campo metodológico, em relação aos propósitos positivistas já indicados. Dentre os opositores da tradição positivista, percebe-se que Paul Feyerabend está entre aqueles que, mais veementemente, procurou desqualificar os seus pressupostos. Crítico do universalismo metodológico, o pensador defende a tese da validade do "pluralismo metodológico" para distintas pesquisas. A controvertida ideia de que a única possibilidade de não frustrar o progresso do conhecimento é admitindo que "tudo vale", sustentada primeiramente em Contra o método, revela o "relativismo" constitutivo de sua visão epistemológica (FEYERABEND, 2011). Como explica o autor, não se trata de rechaçar toda herança epistemológica produzida até então, mas de mostrar, sobretudo, que normas científicas podem ser subvertidas - inúmeros são os seus exemplos no decorrer da história. Nessa perspectiva, a autonomia do pesquisador, sua influência persuasiva frente a comunidade científica, fazem parte do intrincado modo como as metodologias são definidas e tornadas consensuais. Tendo em conta esta posição epistemológica, Feyerabend (2010, p. 335) assim situa, em termos metodológicos, o Círculo de Viena:

Rodeados por descobertas revolucionárias nas ciências, pontos de vista interessantes nas artes e desenvolvimentos imprevistos na política, os severos fundadores do Círculo de Viena retiraram-se para uma fortaleza restrita e malconstruída. A conexão com a história foi dissolvida; a colaboração estreita entre os pensamentos científicos e a especulação filosófica chegou ao fim; a terminologia estranha às ciências o os problemas sem relevância científica assumiram o comando.

Não se trata, contudo, nesse estudo de concentrar esforços na desqualificação das formas de positivismo. Até porque é visível a contribuição desta tradição na História das Ciências. Diversamente, o objetivo ao caracterizá-lo como um constructo epistemológico é, acima de tudo, indicar sua influência presente em distintas metodologias preponderantes nas ciências sociais. Assim, é relevante indicar tanto a sua influência na Escola Neoclássica, como também (tal qual será verificado) como Williamson se situa em relação aos pressupostos teóricos da Escola.

\section{Um Olhar Epistemológico sobre a Economia dos Custos de Transação (ECT)}

Como afirma Fiani (2011), convencionou-se distinguir entre duas escolas institucionalistas: a Velha Economia Institucional e a chamada Nova Economia Institucional, cuja diferença reside no fato de que a primeira tem precedência histórica sobre a segunda.

\subsection{A "Velha" e a "Nova" Economia Institucional}

Tanto a "velha" como a "nova" economia institucional são corpos teóricos muito heterogêneos (GUEDES, 2000). No caso da "velha" economia institucional, as suas principais características são encontradas em autores como Marx e Pareto (BASLÉ, 1998). No entanto, como escola de pensamento econômico, os primeiros economistas institucionalistas foram vinculados à escola histórica alemã do final do século XIX. Idealistas, nacionalistas, empiricistas, influenciados pela biologia darwinista, seus principais representantes - e.g., Gustav Schmoller; Adolph Wagner e Wilhem Roscher - construíram o institucionalismo alemão a partir da crítica aos economistas clássicos liberais.

O historicismo alemão recusava a hipótese da possibilidade de uma ordem socioeconômica autorregulada repousar exclusivamente nos atributos individuais de racionalidade e liberdade. Ao criticarem o caráter abstrato e a-histórico das análises dos economistas liberais, reivindicavam a dimensão histórica dos fenômenos econômicos, propondo substituir a análise dos indivíduos às instituições e sua evolução (GUEDES, 2000). A escola institucionalista alemã ganhou adeptos nos Estados Unidos, influenciando uma geração de economistas até a segunda metade da década de vinte, entre eles Thorstein Veblen (2005) e John R. Commons (1936).

Os institucionalistas valorizaram a dimensão histórica dos eventos socioeconômicos e realçaram o foco no coletivo em detrimento à ação individual (SCOTT, 2008). Além disso, a proposta do velho institucionalismo substitui o conceito de equilíbrio pelo de processo evolucionário (DOSI, NELSON, 1994; PAULRÉ, 1997), recusando a pretensão neoclássica 
de construir uma teoria "geral" (universal e a-histórica) para a ciência econômica, propondo o deslocamento da centralidade analítica do indivíduo para a instituição (GUEDES, 2000). Para Hodgson (1998, p. 172), o fato de que as instituições tipicamente registram um grau de invariância ao longo de extensos períodos de tempo e podem sobreviver aos indivíduos, oferecem as razões para escolhê-las ao invés dos indivíduos como unidade básica. A maioria das instituições precede temporalmente aos indivíduos, que com elas se relacionam. Nós nascemos e somos socializados dentro de um mundo de instituições. Ao reconhecer isto, os institucionalistas centram-se sobre os traços específicos de instituições específicas ao invés de construir um modelo geral $e$ a-histórico do agente individual.

Nesses termos, a abordagem do velho institucionalismo recusa o individualismo metodológico. Na sua visão, os indivíduos não apenas são constrangidos $e$ influenciados, mas, em grande medida, constituídos pelas instituições. Assim, o caráter estável e permanente das instituições ser compreendido pelo papel dos hábitos em sustentar o comportamento individual e oferecer aos indivíduos os meios cognitivos pelos quais a informação recebida possa ser interpretada e entendida. O resultado é que os comportamentos econômicos são deslocados do indivíduo atomizado para um padrão institucional de interações sociais determinadas historicamente. (GUEDES, 2000)

\subsection{A Nova Economia Institucional (NEI)}

A Nova Economia Institucional teve as primeiras contribuições em The Nature of the Firm de Coase (1937), mas criou forma e foi desenvolvida por Williamson a partir de sua trilogia (Markets and Hierarchies, 1975; The Economic Institutions of Capitalism, 1985; The Mechanisms of Governance, 1996) e diversos outros trabalhos (1979, 1991, 1993, 2000). Em consonância com o "velho" institucionalismo, a Nova Economia Institucional reconhece a diversidade de instituições que afetam a sociedade e tem como objetivo explicar o que são as instituições, como elas surgem, para qual propósito elas existem e como ela se transformam (ISNIE, 2014). Contudo, o quadro conceitual no qual a NEI se posiciona opõe-se em muitos aspectos com a sua escola antecessora.
A NEI foi constituída a partir de dois campos de pesquisa complementares. Primeiramente, o ambiente institucional, que tem como objeto de estudo questões como contratos, leis, normas, costumes, convenções, entre outros e arranjo institucional, que trata dos mecanismos de governança das firmas (WILLIANSON, 1996). Assim, a NEI possui um nível de análise macro e um micro. Ambas vertentes são enraizadas no trabalho de Coase, no entanto, a primeira evoluiu através do trabalho de Douglass North e a segunda - objeto de pesquisa deste trabalho - nas contribuições de Oliver Williamson. (ZYLBERSZTAJN; NOGUEIRA, 2002)

\subsection{A Economia dos Custos de Transação a partir da visão de Williamson}

Williamson $(1985,1991)$ propõe como objetivo central compreender as origens e funções das diversas estruturas da empresa e do mercado (das instituições econômicas do capitalismo). Como a utilização do mecanismo de mercado implica custos - identificados e batizados de custos de transação por Coase Williamson se propõe estudar como essas instituições (mercados, firmas e contratos) tratam os problemas vinculados à transação. Considera-se, portanto que as instituições econômicas do capitalismo têm como função principal, embora não exclusiva, a de reduzir os custos de transação. (WILLIAMSON ,1985, 17)

A influência de Coase sobre Williamson e sobre toda uma geração de economistas norte-americanos é reconhecida, assim como suas divergências. No livro Mercados e Hierarquias (1991), Williamson comenta a evolução da sua teoria em relação ao estudo seminal de Coase:

As principais diferenças entre os trabalhos anteriores e o enfoque adotado aqui são: 1) dedico-me muito mais que os autores citados a investigar os aspectos de racionalidade limitada; 2) introduzo explicitamente a ideia de oportunismo e me interesso pelas formas nas quais $\mathrm{o}$ comportamento oportunista está determinado pela organização econômica, e 3) sublinho que não é a incerteza nem os números pequenos, na forma individual ou em seu conjunto, o que ocasiona as falhas de mercado, mas a reunião destes fatores com a racionalidade limitada, por uma parte, e o oportunismo, por outra, o que traz dificuldades no intercâmbio. (WILLIAMSON, 1991, p. 23) 
Nesse sentido, pode-se considerar que a divergência principal reside no fato de que o insigth de Coase, que lhe permitiu perceber a importância dos custos de transação e a possibilidade de falhas de mercado, não foi plenamente aproveitada em razão da inexistência de uma articulação entre o comportamento/atributos dos agentes e os custos de transação que lhe permitisse explicar porque os custos de transação seriam maiores em certas situações que em outras. Somente a partir da atribuição de hipóteses comportamentais adequadas, e após identificar as características das transações que Williamson pode construir uma sólida teoria dos custos de transação. Assim, os condicionantes definidos pela ECT foram: a) o ambiente institucional (formal e informal); b) os pressupostos comportamentais (racionalidade limitada e oportunismo); c) as características das transações (especificidade de ativos, frequência das transações e incerteza nas transações).

Na obra de Williamson (1991), a eficiência ocupa papel de destaque. Apesar de rejeitar a concepção tradicional que limita esse conceito a uma mera questão quantitativa, i.e., a alocação mais produtiva dos insumos, Williamson ressalta a importância da capacidade evolutiva das instituições, na direção de um arranjo mais eficiente para o emprego mais eficiente dos recursos na sociedade (WILLIAMSON, 1991). A diferença fundamental em relação à teoria neoclássica é a de que - enquanto esta assume uma tendência natural de convergência para um equilíbrio eficiente do sistema econômico - a ECT reconhece a impossibilidade de uma otimização tão completa em virtude da influência de toda a gama de imperfeições de mercado e da incerteza. As decisões são tomadas de acordo com as possibilidades oferecidas a cada momento, não correspondendo necessariamente às escolhas ideais. (WILLIAMSON, 1993)

Para criar um arcabouço teórico frente à complexidade das decisões estratégicas, Williamson (1975, 1991, 1996) enfatiza a necessidade da interdisciplinaridade. Assim, o estudo das transações engloba diferentes disciplinas, como a administração, direito, ciência econômica, sugerindo, no caso desta última, uma ruptura com a abordagem econômica do mainstream, ruptura esta fundamentada em dois pontos principais. Primeiramente, o tratamento dado à firma. Williamson critica a economia neoclássica devido a seu juízo equivocado dado à firma, que é representada fundamentalmente por meio de uma função de produção. Para os neoclássicos, os recursos econômicos disponíveis são organizados e alocados, conforme objetivos maximizadores na qual o mecanismo de preços é suficiente para transmitir as informações e os sinais necessários a essa tarefa. As transações, que supostamente são impessoais e instantâneas no âmbito do mercado, são realizadas com bastante precisão e sem custos. Para Williamson, a firma deve ser tratada como uma estrutura de governança, na qual o objetivo é garantir uma coordenação que economiza os custos de transação, reduzindo a incerteza, compensando os agentes da racionalidade limitada e protegendo-os do oportunismo. Tal governança pode ser através ou não do mercado.

Em segundo lugar, as hipóteses comportamentais atribuídas aos agentes econômicos, como a existência da racionalidade limitada e do oportunismo são fatores determinantes para que exista custos de transação nas relações econômicas intrafirmas.

O conceito de racionalidade limitada é um dos pilares da teoria da Williamson, sendo também uma das grandes diferenças da economia neoclássica. No conceito de racionalidade proposto por Williamson, estão presentes:

a) A incerteza: é impossível ou muito custoso identificar eventos futuros e especificar, ex-ante, as adaptações adequadas a eles.

b) Limitações neurofisiológicas e de linguagem: a racionalidade é limitada em razão, também, de que a mente possui limitações para receber, armazenar, recuperar, processar e analisar informações sem erros. A isso vem se somar as limitações de linguagem, que consiste, nas palavras de Williamson (1975, p. 39) na "[...] incapacidade dos indivíduos de expressar seus conhecimentos ou sentimentos mediante o uso da palavra, de números e gráficos de modo que os outros possam entender".

c) Complexidade: as complexas decisões que enfrentam as firmas implicam a impossibilidade (ou, quando possível, custos proibitivos) de elencar todas as possibilidades e consequências das decisões. Por consequência, na teoria da Williamson os contratos são considerados, invariavelmente, incompletos.

Além da racionalidade limitada, destaca-se o comportamento oportunista, sendo essencial a ideia 
a de que na busca de seu autointeresse, os homens nem sempre se conduzem de maneira transparente e honesta. Nesse sentido, conforme a observação de Williamson (1985, p. 47), oportunismo "[...] inclui, mas certamente não está limitado às formas mais óbvias, tais como a mentira, o roubo e a fraude. O oportunismo envolve na maioria das vezes formas sutis de enganação. Tanto na forma ativa e passiva quanto nos tipos ex-ante e ex-post".

Segundo Williamson (1985), quanto maior for a especificidade dos ativos, ou seja, quanto maior a diferença entre a melhor opção de uso de um ativo e as opções alternativas, mais provável será a opção de internalização da transação dentro da firma (coordenação via hierarquia) ou através de redes (formas híbridas via contratos de longo prazo), ao invés do emprego do mercado. Além da especificidade dos ativos, a decisão pela estrutura de mercado também é influenciada pela frequência e incerteza.

Com relação à frequência, segundo Williamson (1985), sua ocorrência torna-se importante na medida em que pode determinar o surgimento de instituições especialmente alinhadas para sua coordenação e gestão, logo, quanto maior for a frequência de realização de transações, maiores serão os incentivos para o desenvolvimento de instituições que irão gerenciá-las. A frequência refere-se à quantidade de vezes que ocorre a utilização das estruturas, ou acontece a comercialização dos produtos entre os agentes.

Por fim, a incerteza, que é um atributo das transações, exerce influência sobre as características das instituições na medida em que a maior ou menor capacidade dos agentes em prever os acontecimentos futuros pode estimular a flexibilização nos contratos, estando presente também no conceito de racionalidade limitada. (WILLIAMSON, 1985)

\section{Uma Análise Epistemológica da ECT}

Podendo a epistemologia ser entendida como o estudo metódico do saber, sua organização, formação, desenvolvimento e funcionamento de seus produtos intelectuais (JAPIASSU, 1991), este tópico objetiva apresentar uma análise epistemológica da ECT, considerando os estudos de Williamson (1975, 1979, 1985,
1991, 1993, 1996, 2000) e o surgimento da Economia Institucional e da Nova Economia Institucional.

Pode-se considerar que a economia institucionalista surgiu como reação à perspectiva teórico-metodológica contida nas escolas clássica, as quais sustentavam o individualismo metodológico e as analogias mecanicistas do paradigma da física Newtoniana. O "velho" institucionalismo marcou uma ruptura radical com a economia do mainstream ao considerar que os fenômenos econômicos são também históricos e devem ser estudados a partir das instituições e não a partir da análise de indivíduos.

Já em décadas mais recentes, o ressurgimento do "novo" institucionalismo gerou um debate sobre o significado e parentesco com a escola que lhe inspirou o nome. A NEI pode ser considerada como uma perspectiva teórica contemporânea em que as instituições são parte de suas análises, contudo, a sua visão é de que a existência destas instituições é derivada das ações dos indivíduos (HODGSON, 2001; KLEIN, 2000), o que representa uma retomada do individualismo metodológico de Menger (1981).

Segundo Farina (1999), a ECT pretende explicar as diferentes formas organizacionais prevalecentes nos mercados, especialmente no tocante ao grau de interação vertical. Ainda, de acordo com a autora, a ECT trabalha em um ambiente de racionalidade limitada, caracterizado pela incerteza e informação imperfeita. Logo, decorrem dessas duas características os custos de transação, cuja minimização explica os diferentes arranjos contratuais que cumprem a finalidade de coordenar as transações de maneira eficiente.

Em última instância, Williamson busca responder a seguinte questão formulada por Coase (1937): "por que as organizações existem?”. Assim, como tradicionalmente, a teoria econômica procura determinar a alocação ótima dos recursos a partir de um conjunto de organizações econômicas (e.g., famílias, empresas e mercados) consideradas como dadas, a NEI objetiva identificar qual a melhor forma de organização das transações econômicas, cuja configuração altera as condições iniciais para a alocação de recursos.

Verifica-se que, nos trabalhos dos autores da NEI, a crítica à excessiva formalização empregada pelas abordagens organizacionais vinculadas à tradição ortodoxa é recorrente, não se tratando propriamente 
de um ataque ao uso dos modelos matemáticos, como bem salienta Coase (1988), mas antes um alerta sobre os riscos do inevitável prejuízo em termos teóricos decorrente da redução dos fenômenos econômicos às rotinas algébricas. No caso específico da análise do comportamento das firmas, essa excessiva simplificação pode mesmo comprometer por completo a capacidade explanatória da teoria frente à realidade.

Nesse sentido, pode-se dizer que a ECT tenta se afastar do positivismo neoclássico, ao considerar que, além da abordagem objetiva, as firmas/organizações devem ser analisadas sob o ponto de vista subjetivo. Este enfoque pode ser verificado quando Williamson (1990) ressalta a importância da capacidade evolutiva das instituições e rejeita a concepção tradicional que limita o conceito de eficiência a uma mera questão quantitativa. Assim, influênciado por Hayek (1945) e Barnard (1938), Williamson adota a visão de que a adaptação é um problema central da economia e que este problema é consequência das mudanças, tanto no mercado como nas firmas.

Williamson também considera a influência da natureza do sujeito no ambiente econômico. Fundamentada em Herbert Simon (1997, original 1947), a ECT considera a racionalidade limitada dos agentes, fator até então negligenciado pelas teorias econômicas tradicionais, como pressuposto comportamental. Reconhecendo que os indivíduos são incapazes cognitivamente de prever todas as contingências na assinatura dos contratos, a ECT parte da premissa de que todos os contratos são inexoravelmente incompletos, o que faz com que a empresa seja considerada uma estrutura de governança antes que uma simples função de produção. (KLEIN, 2000)

Ainda sobre a ação dos indivíduos, é possível considerar que a abordagem trazida por Williamson de certa forma inovadora, pois enquanto os economistas tradicionais simplesmente consideram que os atores econômicos comportam-se de forma isenta, a ECT leva em conta a possibilidade da busca do interesse próprio com astúcia, i.e., o comportamento oportunista.

A eficiência é um dos conceitos centrais da ECT. Salienta-se, no entanto, que no caso desta teoria a eficiência não é avaliada ou buscada somete em termos quantitativos, conforme já evidenciado anteriormente, pois, ao considerar a influência do indivíduo, seja pelo oportunismo ou racionalidade limitada, a ECT sugere também uma visão $e$ análise subjetiva para as decisões que envolvem as firmas e organizações. Além disso, a empresa passa por escolhas (trade-off) $e$, como economizadora de custos de transação, a forma de organizar uma atividade decorre da escolha entre os custos burocráticos da integração vertical e os custos contratuais da contratação via mercado ou de formas híbridas. Estes custos variam de acordo com as características da transação e a ECT pressupõe que os arranjos observados na prática, sob um determinado ambiente institucional, decorrem dessas escolhas.

Nesse ponto, autores, como por exemplo Foss (1994), consideram que a ECT acaba por retornar ao viés neoclássico de pesquisa, uma vez que o agente passa de um maximizador de riqueza para um minimizador de custos de transação. No entanto, a partir da leitura dos trabalhos de Williamson, observa-se que o autor vê a firma como parte de um sistema maior, que pode ser uma cadeia, uma rede, um arranjo. Assim, a firma sofre influência tanto como também influencia o ambiente em que está inserida, e este ambiente institucional é, em parte, responsável pelos custos de transação enfrentados pelas firmas.

Ao propor estruturas de governança, pode-se considerar que a ECT visa "regular" a firma e as organizações da qual faz parte. Ao tratar da estrutura de governança, parte-se da visão sistêmica, na qual as organizações são definidas como conjunto, cujas partes são relacionadas, necessitando de coordenação e de estrutura de autoridade para tal, visando o atingimento de metas e objetivos.

Nesse sentido, é possível citar Selzinick (1967), para o qual a abordagem funcionalista considera que a organização formal seja um sistema de atividades coordenadas entre duas ou mais pessoas. Para esse autor, os sistemas falham pelo fato de não considerarem os aspectos informais. Além disso, cita que a análise estrutural $e$ funcional relaciona o comportamento contemporâneo e variável a um sistema de necessidades e a um mecanismo presumivelmente estável. A ECT tem características funcionalistas ao visar à coordenação $e$ ao controle, no entanto, apesar da vertente da NEI que estuda o ambiente institucional considerar ambiente institucional é composto por regras informais, que podem ser sanções, costumes, tradições, códigos de conduta, além das regras formais, que correspondem as constituições e as leis (NORTH, 1990; 1998), a ECT 
não considera as instituições informais dentro do seu modelo teórico.

Ao considerar os aspectos sistêmicos, novamente é possível inferir que a ECT tem uma concepção baseada nos pressupostos funcionalistas $e$ sistemistas, regidos pelas premissas das ciências naturais (visão de sistema) que permeiam o paradigma dominante nas ciências sociais, que valoriza o controle, coordenação e equilíbrio. O controle e coordenação são facilmente identificados na ECT, visto que, segundo Williamson, a governança deve ser estabelecida visando tais características, buscando reduzir incerteza e oportunismo. Nesse sentido, cita-se Chanlat (1987), que apresenta quatro formas de organização: a) sistêmica e sincrônica: organização definida como um conjunto de partes sincronizadas uma na outra, coordenada em busca de uma maior eficácia, a partir de uma estrutura de autoridade; b) teleológica: a coordenação dos indivíduos e das suas atividades é orientada para o alcance de metas e objetivos; c) a-histórica: a história da organização se resume à avaliação de informações quantitativas; d) integradora e não conflitual: a organização caracteriza-se pelo consenso e não pela existência de relações de poder e conflito. Dentre as quatro formas de organização apresentadas por Chanlat (1987) é possível dizer que a ECT tem características da forma sistêmica e sincrônica.

Salienta-se com maior ênfase a teoria geral dos sistemas, na qual há uma hierarquia, cuja coordenação se dá por intermédio de uma empresa exercendo poder sobre as demais. No caso da ECT, pode-se considerar que o poder existe tanto na estrutura de hierarquia (internalização dos custos de transação), na qual uma empresa assume poder sobre as demais, como nos casos de mercado, sendo que neste último caso o "poder" se estabelece por intermédio dos contratos. Segundo Demo (1985), no sistemismo há traços no funcionalismo e a significação de sistema está na interrelação entre as partes. Além disso, cita-se Kast e Rosenweig (1976), para os quais a concepção de sistema aberto obriga as organizações a lidar com incertezas, ambiguidades e, acima de tudo, a preocupação com o ajuste da organização a novos requisitos, que estão em constante mudança.

\section{Considerações Finais}

A ECT analisada a partir dos trabalhos de Williamson tem como base a definição da firma como um conjunto de contratos, sendo que o objetivo principal das firmas é reduzir os custos de transação. Nessa teoria, a firma é vista como parte de um sistema maior, que pode ser uma rede, cadeia, arranjo. Visando minimizar os custos de transação, os diferentes "arranjos" ou firmas decidem por estruturas de governança, que pode ser hierarquia, mercado ou forma híbrida. A decisão pela estrutura de governança mais adequada deve levar em consideração fatores como: incerteza, especificidade dos ativos e frequência. O oportunismo e a racionalidade limitada são conceitos centrais desta teoria.

$\mathrm{Na}$ ECT há forte influência do capitalismo, da busca constante por eficiência por meio da melhor escolha possível que minimize os custos de transação. Alguns dos conceitos da teoria sugerem diferentes perspectivas epistemológicas, sendo possível identificar características do funcionalismo, do sistemismo, da dialética e da complexidade, não sendo possível caracterizar essa teoria em apenas uma das abordagens teóricas citadas. No entanto conceitos como estrutura de governança, que remete a coordenação e controle estão presentes de maneira muito forte nesta teoria, aproximando-a mais das visões: funcionalista e sistêmica, derivados do positivismo.

Tal evidência corrobora com a visão de autores como Chevallier e Loschak (1982), Guerreiro Ramos (1989), Audet e Déry (1996), Garcia e Bronzo (2000), Serva (2001), para os quais o positivismo influencia fortemente a geração de conhecimento nas ciências sociais. Corroborando com esta afirmação, cita-se Serva, Dias e Alperstedt (2010), quando afirmam que, apesar da necessidade de explicar o fenômeno organizacional a partir do desenvolvimento de teorias mais complexas e profundas, observa-se ainda, na grande maioria das pesquisas, métodos tradicionais de orientação positivista e funcionalista.

No entanto, já no final do século passado e início deste, verifica-se uma perspectiva de mudança com discussão do paradigma emergente, considerando que o conhecimento não é único, mas parcial, e que 
não pode ser externo ao sujeito. Não por isso deve-se desconsiderar todo o conhecimento gerado pelo paradigma dominante, pois se entende que o "pluralismo de ideias" é benéfico à geração de conhecimentos e estudos das ciências administrativas.

Cita-se Guerreiro Ramos (1989), que critica a racionalidade ocidental dominante, considerando que esta se condenou a permanecer pré-analítica e na periferia da ciência social. O autor considera a necessidade de tornar visíveis movimentos alternativos às firmas/ organizações sustentadas pelo paradigma dominante. Defende a teoria substantiva, destacando que em uma sociedade formal a sobrevivência dos indivíduos é assegurada pelos critérios globais de reciprocidade, redistribuição e troca, enquanto em uma sociedade moderna (substantiva), as grandes organizações atendem as necessidades dos indivíduos. Para o autor explica na sociedade moderna a organização formal (burocrática) tornou-se um modelo fundamental e, neste sentido, discute a questão social inerente às organizações formais, visto que o sistema de mercado não pode funcionar em bases puramente técnicas e econômicas, existindo também a questão dos trabalhadores envolvidos.

Nesse sentido, Guerreiro Ramos (1989) propõe uma nova abordagem para a ciência das organizações, fazendo, sobretudo, uma crítica à estrutura de sociedade centrada no mercado, sendo organizações formais fundadas em cálculo, constituindo sistemas projetados, criados deliberadamente para a maximização dos recursos. Na tentativa de criar e maximizar os recursos necessários a seu bem-estar material, o indivíduo permite-se a atividades específicas da organização econômica formal. No entanto, regras operacionais, mecânicas, não se ajustam a todo o espectro da conduta humana. Considera que o conceito básico da razão prescreve como os seres humanos devem ordenar sua vida pessoal e social, denunciando o impacto sobre a vida humana. Na sociedade de mercado, caracterizada pela racionalidade instrumental, o ser humano é uma criatura de cálculo utilitário.

Guerreiro Ramos (1989) sustenta então a racionalidade substantiva como ponto de referência para a ordenação da visa social e para a estruturação da vida humana. Defende uma visão multifacetada da sociedade, composta por numerosos aspectos (político, econômico, estrutura social, cultural, psicológico). Tem-se um homem complexo, com diferentes neces- sidades e interesses, cuja satisfação requer múltiplos cenários sociais e espaços organizacionais adequados à atualização pessoal, a relacionamentos de convivência e atividades comunitárias dos cidadãos. Em sua abordagem substantiva da organização, considera a isonomia (formas possíveis de ambientes igualitários, sem burocracia, sem hierarquia). Não acredita na ausência de normas, mas espera que o próprio indivíduo, em um contexto de escolha, possa definir as suas próprias normas.

Para Serva (1997), a sobrevivência das organizações é prioritária à sobrevivência do indivíduo; a sociedade do produtivismo, instituindo exageradamente o trabalho, onde os indivíduos são avaliados em função do seu status. De uma maneira geral, a busca incessante pela vantagem competitiva das organizações, sem considerar os efeitos nefastos de tais práticas, não considerando o contexto social e sem o julgamento ético das organizações são fatores que tem aprofundado a crise.

Verifica-se uma clara posição dos autores pela necessidade de mudança do paradigma organizacional predominante, no qual a maximização dos resultados, o foco no mercado, são as bases das ações organizacionais, sendo o indivíduo um "artefato" neste contexto.

Apesar da manifestação desses e de outros autores e pesquisadores, o que se verifica ainda é a grande influência que o paradigma dominante confere às ciências sociais. Há uma grande dificuldade em desvencilhar-se desta abordagem, visto que foi e ainda é predominante nas diversas universidades. Os atuais cientistas são fruto dessa base epistemológica. Mesmo quando tentam desenvolver um estudo baseado no paradigma emergente, têm dificuldades, e muitas vezes, apesar de tentar, não conseguem fazer. Não sabem, em muitos casos, sequer trabalhar interdisciplinaridade, necessidade esta oriunda a partir da separação, especialização que o paradigma dominante criou, sendo mais complexo e difícil ainda colaborar na reconstrução da reciprocidade e solidariedade que, é possível dizer, nem consideradas são nas organizações capitalistas e na maioria das pesquisas nas ciências sociais, especialmente administração e economia.

Mas, apesar dessas inquietações, entende-se que há um processo lento em transição, sendo possível verificar algumas mudanças, novas formas de entender 
e gerar conhecimento na ciência social. Acredita-se ainda que, só o fato de considerar que há necessidade de mudança e identificar qual a direção que se espera no estudo da administração, já é um grande avanço. A ruptura necessária, apontada pelos autores, é difícil e demorada, no entanto, pode ser a alternativa para uma verdadeira evolução no estudo da administração, evitando que se torne uma ciência vazia, distante da realidade social e presa a antigas referências locais e formais, como citado por Garcia e Bronzo (2000), desconsiderando a história, a cultura, as pessoas.

\section{REFERÊNCIAS}

AUDET, Michel; DÉRY, R. La science réfléchie quelques empreintes de l'épistémologie des sciences de l'administration. Anthropologie et Sociétés, Laval, v. 20, n. 1, 1996.

BACON, F. Novumorganum ou verdadeiras indicações acerca da interpretação da natureza. Tradução e notas J. A. R. de Andrade. São Paulo: Abril Cultural, 1979. p. $1-122$

BARNARD, C. I. The functions of the executive. Boston, MA: Harvard University Press, 1968 [1938].

BASLÉ, M. Mise en perspective de l'institutionnalisme de quelques économistes allemandes et américains. Économie Appliquée, Grénoble, v. 46, n.4, 1993. p. 159-176.

BENTHAM, J. Uma introdução aos princípios da moral e da legislação. 2. ed. São Paulo: Abril Cultural, 1979.

BRAGA, R. S.; A. F. S. BRAGA. Positivismo e construtivismo nas teorias do conhecimento e das organizações. Rio de Janeiro: Contraponto, 2014.

BUCKLEY, Walter Frederick. A sociologia e a moderna teoria dos sistemas. São Paulo: Cultrix: Ed. Univ. S. Paulo, 1971.

CHANLAT, J. F.; SÉGUIN, F. O paradigma funcionalista e sua concepção da organização (trad. livre);

O paradigma crítico em sociologia (trad. livre);

O paradigma crítico e sua concepção da organização (trad. livre). In: TOME, I. L'analyse des organisations: une anthologie sociologique. Montreal: Gaëtan-Morin, 1987.

\section{CHEVALLIER J.; LOSCHAK, D. A ciência}

administrativa. Coleção Saber. Lisboa: Publicações

Europa-américa, 1982.

COASE, R. The nature of the firm. Economica, London, v. 4, p. 396-405, 1937.

The firm, the market and the law. Chicago:

The University of Chicago Press. 1988. 217 p.

COMTE, A. Curso de filosofia positiva: discurso sobre o espírito objetivo, catecismo positivista. São Paulo: Abril Cultural, 1978. (Os pensadores)

\section{CONCEIÇÃO, O. A. C. Instituições, crescimento} e mudança na ótica institucionalista. 1. ed. Porto Alegre: Fundação de Economia e Estatística, 2002. 228 p.

DEMO, P. Base empírica da pesquisa social; Abordagem sistêmica e funcionalista - visão dinâmica dentro do sistema; Sociedade provisória - perspectivas de uma metodologia processual dialética. In: DEMO, P. Metodologia científica em ciências sociais. São Paulo: Atlas, 1985.

DESCARTES, R. Discurso do método: meditações, objeções e respostas, as paixões da alma, cartas. Tradução de J. Guinsburg e B. Prado Júnior. São Paulo: Abril Cultural, 1979. p. 39-41.

DORTIER, J. F. Le cercle de Vienne et le nouvel sprit scientifique. Sciences Humaines, Paris, hors-série, septembre, 2000.

DOSI, G.; NELSON, R. An Introduction to evolutionary theories in economics. Journal of evolutionary

Economics, [S. 1. ], v. 4, n. 3, p. 153-172, 1994.

DURKHEIM, Émile. As regras do método sociológico (Cap. primeiro). Da divisão do trabalho social (livro I, cap. 1). In: DURKHEIM, Émile. Coleção os pensadores. São Paulo: Abril Cultural, 1978.

FARINA, E. M. Q. Competitividade e coordenação dos sistemas agroindustriais: a base conceitual. In: JANK, Marcos S. et al. Agribusiness do leite no Brasil. São Paulo: IPEA, 1999.

FARINA, E. M. Q.; AZEVEDO, P. F. de; SAES, M. S. M. Competitividade: mercado, estado e organizações. São Paulo: Singular, 1997. 
FARINA, E. M. Q.; ZYLBERSZTAJN, D.

Competitividade e organizações das cadeias

agroindustriais. Costa Rica: Instituto Interamericano de Cooperação para a Agricultura, 1994.

- Organização das cadeias agroindustriais

de alimento. In: ENCONTRO NACIONAL DE

ECONOMIA,1992, Campos de Jordão, p. 189-207.

Anais... São Paulo, 1992.

FEYERABEND, P. Adeus à razão. São Paulo: Editora Unesp, 2010.

FEYERABEND, P. A ciência em uma sociedade livre. São Paulo: Editora Unesp, 2011.

FIANI, R. Cooperação e conflito: instituições e desenvolvimento econômico. Rio de Janeiro: Elsevier, 2011.

FOSS, N. J. The theory of the firm: The Austrians as precursors and critics of contemporary theory. The

Review of Austrian Economics, [S.1.], v. 7, n. 1, p. 3165, 1994.

GARCIA, F. C.; BRONZO, M. As bases epistemológicas do pensamento administrativo convencional e a crítica à teoria das organizações. In: I ENEO. Curitiba, 2000.

Anais... Curitiba, 2000.

GUEDES, Sebastião Neto Ribeiro. Observações sobre a economia institucional: há possibilidade de convergência entre o velho e o novo institucionalismo? In: V ENCONTRO NACIONAL DE ECONOMIA POLÍTICA, Fortaleza, 21 a 25 de julho de 2000. Anais... Fortaleza, 2000.

\section{GUERREIRO RAMOS, Alberto. A nova ciência das} organizações: uma reconceituação da riqueza das nações. Rio de Janeiro: FGV, 1989.

A racionalidade substantiva demonstrada na prática administrativa. Revista de Administração de Empresas, São Paulo, v. 37, n. 2, p. 18-30, abr.-jun. 1997.

Abordagem substantiva e ação comunicativa: uma complementaridade proveitosa para a teoria das organizações. Revista de Administração Pública, Rio de Janeiro, v. 31, n. 2, p. 108-34, mar.-abr. 1997.
HAYEK, F. A. The use of knowledge in society. The American economic review, [S.1.], p. 519-530, 1945.

HYRATUKA, C. Estruturas de Coordenação e Relações Interfirmas: uma interpretação a partir da Teoria dos Custos de Transação e da Teoria Neo-Shupteriana.

Economia de Empresa, São Paulo, v. 4, n. 1, p. 17-23, jan.-mar. 1997.

HODGSON, G. The approach of institutional economics. Journal of Economic Literature, Pittsburgh, v. 36, p. 166-192, 1998.

A evolução das instituições: uma agenda para pesquisa teórica futura. Economica, Chicago, v. 3, n. 1, p. 97-125, 2001.

JAPIASSU, H. Alguns instrumentos conceituais. O que é a epistemologia? In: JAPIASSU, H. Introdução ao pensamento epistemológico. Rio de Janeiro: Francisco Alves, 1991.

KAST, F. K.; ROSENZWEIG, J. E. Organização e administração: um enfoque sistêmico. São Paulo: Pioneira, 1976.

KLEIN, P. New institutional economics. In: BOUCKEART, B.: GEEST, G. (Ed.). Encyclopedia of Law and Economics. Cheltenham: Edward Elgar, 2000. p. 456-489.

MENGER, C. Principles of economics. Auburn, AL: Ludwig von Mises Institute, 1981 [1871].

MYNAIO, M. C. de S. O desafio do conhecimento: pesquisa qualitativa em saúde. São Paulo: Hucitec, 2014.

PARSONS, Talcott. Sugestões para um tratado sociológico da teoria de organização. In: ETZIONI, A. (Org.).

Organizações complexas. São Paulo: Atlas, 1967.

PADOVANI, U.; CASTAGNOLA, L. O positivismo. In: PADOVANI, U.; CASTAGNOLA, L. História da filosofia. São Paulo: Melhoramentos, 1990. p. 428-439. O criticismo kantiano. O positivismo. In: PADOVANI, U.; CASTAGNOLA, L. História da filosofia. São Paulo: Melhoramentos, 1990. p. 358-379.

PAULRÉ, B. Évolutionnisme contemporain et autoorganisation. Économie Appliquée, Paris, n. 3, p. 121150, 1997. 
PIMENTA, P. P. G. Kant e a Revolução Copernicana: a razão reflete sobre si mesma. Mente, cérebro \& filosofia: fundamentos para a compreensão da psique. São Paulo: Duetto, 2008. p. 14-19.

\section{PRIGOGINE, I.; STENGERS, I. A nova aliança:} metamorfose da ciência. 3. ed. Brasília, DF: Ed. Universidade de Brasília, 1997.

POPPER, K. A lógica da investigação científica. In: POPPER, K. Coleção os pensadores. São Paulo: Abril Cultural, 1980.

\section{RADCLIFFE-BROWN, A. R. Estrutura e função na} sociedade primitiva. Petrópolis: Vozes, 1973.

\section{ROSENWEIG, J.; KAST, F. Organização e}

administração: um enfoque sistêmico. São Paulo:

Pioneira, 1980.

SELZNICK, P. Fundamentos da teoria de organização. In: ETZIONI, A. (Org.). Organizações complexas. São Paulo: Atlas, 1967.

SERVA, M. O paradigma da complexidade e a análise organizacional. Revista de Administração de Empresas, São Paulo, v. 32, n. 2, p. 26-35, abr.-jun. 1992.

O fato organizacional como fato social total.

Revista de Administração Pública, Rio de Janeiro, v. 35, n. 3, p. 131-152, 2001.

. O Surgimento e o desenvolvimento da

epistemologia da administração: inferências sobre a contribuição ao aperfeiçoamento da teoria administrativa. In: ENCONTRO NACIONAL DA ANPAD, 36, 2012. Rio de Janeiro. Anais... Rio de Janeiro: ANPAD, 2012.

SERVA, M.; DIAS, T.; ALPERSTEDT, G. Paradigma da complexidade e teoria das organizações: uma reflexão epistemológica. Revista de Administração de Empresas, São Paulo, v. 50, n. 3, p. 276-287, jul.-set. 2010.

SIMON, H. Administrative behaviour: a study of decision-making process in administrative organization. 4th Ed. New York: The Free Press, 1997.

WILLIAMSON, O. E. Markets and hierarchies: analysis and antitrust implications. New York: Free Press, 1975.
Transaction Cost Economics: The Governance of Contractual Relations. Journal of Law and Economics, New York, v. 22, p. 233-261, 1979.

\section{The Economic Institutions of Capitalism:}

firms, markets, relational contracting. New York: The Free Press, 1985.

Mercados y Jerarquías: su análisis y sus implicaciones antitrust. México, DF: Fondo de Cultura Económica. 1991. 318p.

Transaction Cost economics and organization.

Strategic Management Journal, Chicago, v. 12, p. 7594, 1993.

The mechanisms of governance. New York: Oxford University Press, 1996.

The new institutional economics: taking stock, looking ahead. Journal of Economic Literature, Pittsburgh, v. XXXVIII, p. 595-613. Sep. 2000. 